\title{
Video-assisted thoracoscopic bullectomy and talc poudrage for spontaneous pneumothoraces: Effect on short-term lung function
}

\author{
Luc Dubois, MD, and Richard A. Malthaner, MD, MSc, FRCSC, FACS
}

\begin{abstract}
Objective: We measured lung function before and after video-assisted thoracoscopic apical bullectomy and talc poudrage in patients with spontaneous pneumothoraces.

Methods: Seventy-two patients were prospectively followed up for 12 months. The indications for surgery were recurrent pneumothoraces $(\mathrm{n}=58)$, bilateral pneumothoraces $(\mathrm{n}=8)$, and persistent air leak $(\mathrm{n}=6)$. There were 46 males and 26 females with mean age of 29 years (range 15-61 years). The results were analyzed using paired $t$ tests.
\end{abstract}

Results: There were no recurrences. There were 4 complications (5.6\%): 1 wound infection, 1 case of pneumonia, and 2 persistent air leaks each lasting 1 week. There were no conversions to open surgery. Preoperative and 6-month pulmonary function test results were available on 41 patients, and 35 patients completed 12-month pulmonary function tests. Twelve-month values (mean percent $\pm \mathrm{SD}$ ) were as follows: Forced expiratory volume in 1 second fell from $95 \pm 19$ to $89 \pm 16(P=.02)$; forced expiratory volume in 1 second/forced vital capacity ratio was unchanged, $95 \pm 12$ versus $94 \pm 13(P=.9)$; total lung capacity fell from $106 \pm 19$ to $98 \pm 12(P=0.002)$; vital capacity fell from $100 \pm 22$ to $96 \pm 16(P=.05)$; residual volume fell from $126 \pm 32$ to $107 \pm 29(P=.002)$; and diffusion capacity for carbon monoxide corrected for alveolar volume was unchanged, $88 \pm 15$ versus $91 \pm 17(P=.07)$. Flow rates and diffusion capacities were preserved, but lung volumes were slightly reduced at 1 year.

Conclusions: Video-assisted thoracoscopic apical bullectomy and talc poudrage is an effective treatment for spontaneous pneumothoraces with a low complication rate and recurrence rate and only minor changes in pulmonary function at 1 year. (J Thorac Cardiovasc Surg 2010;140:1272-5)

Primary spontaneous pneumothorax is a condition that often affects young, otherwise healthy patients. Operative therapy, when indicated, requires resection of identifiable blebs and obliteration of the pleural space. Controversy exists in the method of pleural obliteration. Most authors perform some form of mechanical pleurodesis with either pleurectomy or pleural abrasion. When performed videothoracoscopically, these approaches are associated with higher recurrence rates than are open procedures. ${ }^{1}$ Video-assisted thoracoscopic (VATS) bullectomy and talc poudrage has emerged as an effective technique, with a recurrence rate of less than $2 \%$ in the largest study to date. ${ }^{2}$ Few studies have examined the effect of talc on lung function, ${ }^{3-5}$ and no study has compared preoperative to postoperative lung function after talc poudrage and bullectomy. In addition, none of these studies was prospective, and it is unclear how patients were

From the Division of Thoracic Surgery, Department of Surgery, The University of Western Ontario, London, Ontario, Canada.

Disclosures: None.

Received for publication March 15, 2010; revisions received May 24, 2010; accepted for publication June 20, 2010; available ahead of print July 20, 2010.

Address for reprints: Richard A. Malthaner, MD, MSc, FRCS, FACS, Division of Thoracic Surgery, London Health Sciences Centre, 800 Commissioners Rd E, Suite E2-124, London, Ontario, Canada N6A 5W9 (E-mail: Richard.Malthaner@ lhsc.on.ca).

0022-5223/\$36.00

Copyright (c) 2010 by The American Association for Thoracic Surgery doi:10.1016/j.jtcvs.2010.06.026 selected for lung function tests. Some concern remains regarding the effect of talc on lung function. ${ }^{6}$ We measured lung function before and after VATS bullectomy and talc poudrage in a prospectively enrolled cohort of patients with spontaneous pneumothoraces. Our objectives were to determine the effect of talc on short-term lung function and to assess clinical outcomes. We hypothesized that talc poudrage would be effective in preventing recurrences and have minimal effect on pulmonary function in patients undergoing apical bullectomies for spontaneous pneumothoraces.

\section{METHODS}

\section{Patients}

From 1999 to 2006, 72 consecutive patients treated with VATS apical bullectomy and talc poudrage for spontaneous pneumothoraces were prospectively followed up and their information entered into a database approved The University of Western Ontario ethics review board. Patient characteristics are shown in Table 1 . Indications for surgery included ipsilateral recurrent or bilateral pneumothoraces or persistent air leak despite chest tube drainage for 7 days. All patients underwent clinical assessment and chest radiographs at 1,6 , and 12 months postoperatively. Pulmonary function tests (PFTs) were performed preoperatively and at 6 and 12 months postoperatively. Pneumothorax recurrence was assessed by chest radiograph and defined as any visible pneumothorax as detected by a blinded radiologist. Preoperative PFTs were compared with 6- and 12-month values using paired, 2-sided $t$ tests. All PFTs were done at the same laboratory using a standardized protocol. All results are presented as percent predicted adjusted for age, gender, height, and race using the European Coal Miners data set. We report on the results of flow rates (forced expiratory volume in 1 


\section{Abbreviations and Acronyms
ARDS = acute respiratory distress syndrome
$\mathrm{FEV}_{1}=$ forced expiratory volume in 1 second
$\mathrm{FEV}_{1} / \mathrm{FVC}=$ ratio of forced expiratory volume/ forced vital capacity \\ PFT $=$ pulmonary function test \\ $\mathrm{RV} \quad=$ residual volume \\ VATS $=$ video-assisted thoracic surgery}

second $\left[\mathrm{FEV}_{1}\right]$ and ratio of forced expiratory volume/forced vital capacity $\left[\mathrm{FEV}_{1} / \mathrm{FVC}\right]$ ), lung volumes (total lung capacity, vital capacity, and residual volume $[\mathrm{RV}]$ ), and diffusion capacity for carbon monoxide corrected for alveolar volume.

\section{Operative Technique}

All procedures were performed with the patient under general anesthesia with single lung ventilation. Three thoracoscopic ports were used: one 5$\mathrm{mm}$ port placed in the seventh intercostal space mid-axillary line, through which a $5-\mathrm{mm} 30^{\circ}$ thoracoscope was introduced, one 5 -mm port placed in the fifth intercostal space posterior axillary line, and one 12-mm port placed in the fifth intercostals space anterior axillary line. The lung was inspected for any blebs, bullae, or air leaks during ventilation. Any blebs or bullae were removed by wedge resection using a $3.5 \times 45-\mathrm{mm}$ (blue) endoscopic linear stapler (Ethicon Endosurgery, Cincinnati, Ohio). If no bleb or bulla was identified, then a minimal apical wedge resection was performed. Five grams of asbestos-free, sterilized talc (Bryan Corporation, Woburn, Mass) was nebulized into the pleural cavity. One chest tube was placed intraoperatively and removed within 48 hours when there was no an air leak.

\section{RESULTS \\ Clinical Results}

All 72 patients completed 12 months of clinical followup. Abnormalities seen at the time of surgery were recorded according to the Vanderschueren classification ${ }^{7}$ : stage I, no visible lung abnormality; stage II, pleuropulmonary adhesions; stage III, blebs/bullae less than $2 \mathrm{~cm}$; stage IV, bullae more than $2 \mathrm{~cm}$. All patients received the same treatment regardless of stage (Table 2). There were no intraoperative complications and no perioperative deaths. Postoperative

TABLE 1. Patient characteristics

\begin{tabular}{lcc}
\hline & No. of patients & $\%$ \\
\hline Total patients & 72 & 100 \\
Age $(y)$ & 29 (mean) & 15-61 (range) \\
Male & 46 & 64 \\
Female & 26 & 36 \\
Smokers & 35 & 49 \\
Indication for surgery & & \\
$\quad$ Ipsilateral recurrent pneumothorax & 58 & 81 \\
$\quad$ Bilateral pneumothoraces & 8 & 11 \\
$\quad$ Persistent air leak after & 6 & 8 \\
$\quad$ chest tube insertion & & \\
\hline
\end{tabular}

TABLE 2. Clinical results $(n=72)$

\begin{tabular}{lcr}
\hline & No. of patients & $\%$ \\
\hline Vanderschueren stage & & \\
I (no abnormality) & 11 & 15 \\
II (adhesions) & 16 & 22 \\
III (blebs/bullae $<2 \mathrm{~cm}$ ) & 33 & 46 \\
IV (bullae $>2 \mathrm{~cm})$ & 12 & 17 \\
Recurrences $(12 \mathrm{mo})$ & 0 & 0 \\
Complications & 4 & 6 \\
Pneumonia & 1 & \\
Wound infection & 1 & \\
Persistent air leaks & 2 & \\
Conversions to open procedure & 0 & \\
\hline
\end{tabular}

complications occurred in $6 \%$ of patients $(4 / 72)$ and included 1 case of pneumonia, 1 wound infection, and 2 persistent air leaks, defined as more than 7 days with a chest tube. All complications resolved without further surgical intervention. There were no conversions to an open procedure. No recurrent pneumothoraces were detected 12 months after surgery.

\section{PFTs}

No patient reported any significant dyspnea during follow-up. Preoperative and 6-month PFT results were available on 41 patients and on 35 patients at 12 months. Seven patients had a chest tube at the time of the preoperative PFTs. PFTs were analyzed with and without these 7 patients with no change in the results; thus all patients were grouped together. There were no significant differences between patients with 12-month PFTs and patients without 12-month results; thus the subset of patients with complete 12-month PFT results is representative of the total group of patients (Table 3). PFT results are summarized in Table 4. There was a statistically significant $6 \%$ loss of $\operatorname{FEV}_{1}(P=.02)$ but no change in $\mathrm{FEV}_{1} / \mathrm{FVC}$ when comparing preoperative with 12 -month values $(P=.9)$. Mean total lung capacity fell by $8 \%(P=.002)$ when comparing preoperative with 12 -month values, whereas mean vital capacity and mean RV fell by $4 \%(P=.05)$ and $19 \%(P=.002)$, respectively. Diffusion capacity remained unchanged, with a change of $+3 \%(P=.07)$ when comparing preoperative with 12 -month values. All mean 12-month PFT results were above $88 \%$ predicted.

TABLE 3. Comparison of patients with and without 12-month PFTs

\begin{tabular}{lccc}
\hline Characteristic & $\begin{array}{c}\text { Patients } \\
\text { with PFTs }\end{array}$ & $\begin{array}{c}\text { Patients } \\
\text { without PFTs }\end{array}$ & P value \\
\hline N & 37 & 35 & \\
Age (mean, SD) & $32(16)$ & $26(10)$ & .08 \\
Smokers (\%) & $17(46)$ & $18(51)$ & .64 \\
Male (\%) & $25(67)$ & $21(60)$ & .50 \\
\hline
\end{tabular}

PFT, Pulmonary function test; $S D$, standard deviation. 
TABLE 4. Results of pulmonary function tests presented as percent predicted (mean \pm standard deviation)

\begin{tabular}{|c|c|c|c|c|c|}
\hline Test & Preoperative & 6 months & 12 months & Mean paired difference* & $P$ value $\dagger$ \\
\hline No. of patients & 41 & 41 & 35 & & \\
\hline$\% \mathrm{FEV}_{1}$ & $95 \pm 19$ & $90 \pm 17$ & $89 \pm 16$ & $4.0 \pm 8.6$ & .02 \\
\hline$\% \mathrm{FEV}_{1} / \mathrm{FVC}$ & $95 \pm 12$ & $78 \pm 12$ & $94 \pm 13$ & $0.2 \pm 8.1$ & .9 \\
\hline$\%$ TLC & $106 \pm 19$ & $100 \pm 16$ & $98 \pm 12$ & $8.3 \pm 14.7$ & .002 \\
\hline$\% \mathrm{VC}$ & $100 \pm 22$ & $96 \pm 15$ & $96 \pm 16$ & $4.0 \pm 14.2$ & .05 \\
\hline$\% \mathrm{RV}$ & $126 \pm 32$ & $114 \pm 42$ & $107 \pm 29$ & $19.1 \pm 34.7$ & .002 \\
\hline$\%$ DLCO/VA & $88 \pm 15$ & $87 \pm 14$ & $91 \pm 17$ & $-4.1 \pm 8.6$ & .07 \\
\hline
\end{tabular}

$F E V_{l}$, Forced expiratory volume in 1 second; $F V C$, forced vital capacity; $T L C$, total lung capacity; $V C$, vital capacity, $R V$, residual volume; $D L C O / V A$, diffusion capacity for carbon monoxide corrected for alveolar volume. ${ }^{*}$ Between preoperative and 12 -month pulmonary function tests. $\dagger$ Comparing preoperative to 12 months postoperative.

\section{DISCUSSION}

VATS apical bullectomy and talc poudrage has emerged as an effective therapy for patients with spontaneous pneumothoraces requiring operative treatment. In our series of 72 patients, we observed no recurrences at 12 months. In the largest series of 861 patients, Cardillo and associates ${ }^{2}$ reported a recurrence rate of $1.73 \%$ after talc poudrage. These recurrence rates are lower than those reported for patients undergoing pleurectomy or abrasion using a minimally invasive approach. In a systematic review comparing open surgery versus VATS for the treatment of spontaneous pneumothoraces, a 4-fold higher risk of recurrence is seen after the VATS approach $(5.4 \%$ vs $1.1 \%) .{ }^{1}$ This may be attributed to the difficulty in achieving adequate pleural abrasion or pleurectomy during the VATS approach. In comparison, talc poudrage achieves a low recurrence rate when performed as a minimally invasive procedure. The advantages of treating these patients with VATS are reduced hospital stay and less postoperative pain. ${ }^{8}$ Critics of the use of talc cite concerns over the potentially negative effect on lung function, its possible carcinogenesis, and the risk of acute respiratory distress syndrome (ARDS). ${ }^{6,9}$

In our series, we found minimal changes between preoperative and 12-month PFT results. Flow rates $\left(\mathrm{FEV}_{1} / \mathrm{FVC}\right)$ and diffusion capacity (diffusion capacity for carbon monoxide corrected for alveolar volume) were unchanged, although we did see a small decrease in lung volumes at 12 months, mostly owing to a loss of RV. Although statistically significant, these changes are unlikely to be clinically significant; all mean values at 12 months were more than $88 \%$ predicted and no patient reported any significant dyspnea during follow-up, although the long-term effects of talc on lung function remain uncertain.

Cardillo and associates ${ }^{5}$ measured long-term lung function in patients who had undergone either VATS bullectomy and talc pleurodesis or simple drainage 5 years after surgery. They found no difference in long-term lung function between the 2 groups. However, they reported on only 50 of 1065 patients and it is unclear how these patients were selected, inasmuch as they were relatively young compared with their overall cohort and all were nonsmokers. In another study of 75 patients treated with talc poudrage for spontaneous pneumothoraces, lung function was reported 22 to 35 years after treatment. ${ }^{3}$ Similar to our study, these authors found a minor loss of total lung capacity (mean \pm standard deviation, $89 \% \pm 15 \%$ vs $96 \% \pm 12 \%$ ) when comparing patients treated with talc poudrage and patients treated with simple drainage, whereas $\mathrm{FEV}_{1}$ and vital capacity remained unchanged. They also argue that these changes, although statistically significant, are not clinically significant inasmuch as they did not result in any symptomatic impairment even more than 20 years after treatment. In addition to the potential effect of talc on lung function, one must consider the effect of the bullectomy itself. In our series, $63 \%$ of patients had visible bullae resected in addition to the talc poudrage. The reduction in lung volumes, particularly in RVs, may be due to this resection, although no correlation existed between the loss of RV and Vanderschueren stage (Spearman rank correlation 0.02; $P=.92$ ). Horio and colleagues ${ }^{10}$ compared PFTs 6 months after surgery between patients treated with bullectomy alone or bullectomy and mechanical pleurodesis and found no significant differences in volumes or flow rates. Although certainly a consideration, the separate effects of bullectomy and pleurodesis on lung function may not be clinically relevant inasmuch as most surgeons perform a combination of both. The other issue is whether other methods of pleurodesis result in similar changes to lung function. The mild restrictive changes we and other authors ${ }^{3}$ have described after talc pleurodesis may be due to the pleurodesis itself, regardless of method, although there is a lack of data to answer this question.

As to the oncologic risk, the use of asbestos-free talc seems to remove the risk of mesothelioma or lung cancer. In an older study of 210 patients who had undergone pleurodesis with either talc or kaolin 14 to 40 years before data collection, Chappel and coworkers ${ }^{11}$ identified no increase in rates of lung cancer and no cases of mesothelioma. No cases were recorded in a study of more than 800 patients by Cardillo and associates, ${ }^{2}$ although their mean follow-up was only 52.5 months. Viskum, Lange, and Mortensen ${ }^{4}$ did not identify any cases of mesothelioma in 99 patients treated with talc for spontaneous pneumothoraces with 25 
to 30 years of follow-up. A recent review of the occupational literature failed to identify any increased risk of lung cancer mortality after occupational exposure to asbestos-free talc. ${ }^{12}$

The risk of ARDS is rare and closely related to the size of the talc particles used. The majority of cases of ARDS have been reported in patients treated in the United States, where most talc preparations have smaller mean particle sizes than do European preparations. ${ }^{13}$ Cardillo and associates ${ }^{2}$ did not report a single case of ARDs in 861 patients treated with talc. In a prospective cohort study of 558 patients treated with talc for malignant pleural effusions, no cases of ARDS were documented. Authors of this study argue that particle size influences the risk of ARDS, inasmuch as they used talc of a controlled particle size with a mean particle size of $24.5 \mu \mathrm{m}$ and a low percentage of small particles $(<10 \mu \mathrm{m})$. This hypothesis is corroborated by animal studies, in which extrapleural dissemination of talc and lung inflammation were related to the use of talc with a larger percentage of small particle sizes $(<10 \mu \mathrm{m}),{ }^{14}$ and that particle size is more important than talc dose in causing lung inflammation. ${ }^{15}$ In a human study, Maskell and colleagues ${ }^{16}$ show that use of mixed talc resulted in more lung and systemic inflammation than did " graded" talc, which had small particles $(<10 \mu \mathrm{m})$ removed. There are no data on the optimal dose of talc, with doses ranging from 2 to $10 \mathrm{~g} .{ }^{2,17}$ We used $5 \mathrm{~g}$ because $10-\mathrm{g}$ doses have been linked to cases of ARDS, ${ }^{17,18}$ whereas other authors advocate $2-\mathrm{g}$ doses. ${ }^{2,19-21}$ We did not encounter any cases of ARDS. The particle size of our talc was not provided by the manufacturer.

Our study is limited by its short-term follow-up and lack of a control group. Although all 72 patients did return for follow-up, a complete set of PFTs was available in only 35 patients. Although all patients agreed to undergo PFTs, many of them are young university students and it was logistically challenging to bring them into the laboratory to undergo lung function tests. Despite these limitations, our study is strengthened by its prospective enrollment of consecutive patients, blinded outcome assessment, and 100\% clinical follow-up.

In summary, this is the only study comparing prospectively collected preoperative lung function with postoperative values in patients treated with VATS apical bullectomy and talc poudrage. There were no recurrences and only a small loss in lung volumes, whereas diffusion capacity and flow rates were maintained at 12 months after surgery. The current evidence suggests that VATS apical bullectomy and talc poudrage is safe and effective in the treatment of patients with pneumothoraces. However, larger prospective studies with long-term follow-up comparing talc with other forms of pleurodesis are needed to settle the controversy surrounding its use.

\section{References}

1. Barker A, Maratos EC, Edmonds L, Lim E. Recurrence rates of video-assisted thoracoscopic versus open surgery in the prevention of recurrent pneumothoraces: a systematic review of randomised and non-randomised trials. Lancet. 2007;370: 329-35.

2. Cardillo G, Carleo F, Giunti R, Carbone L, Mariotta S, Salvadori L, et al. Videothoracoscopic talc poudrage in primary spontaneous pneumothorax: a singleinstitution experience in 861 cases. J Thorac Cardiovasc Surg. 2006;131:322-8.

3. Lange P, Mortensen J, Groth S. Lung function 22-35 years after treatment of idiopathic spontaneous pneumothorax with talc poudrage or simple drainage. Thorax. 1988;43:559-61.

4. Viskum K, Lange P, Mortensen J. Long term sequelae after talc pleurodesis for spontaneous pneumothorax. Pneumologie. 1989;43:105-6.

5. Cardillo G, Carleo F, Carbone L, Di Martino M, Salvadori L, Ricci A, et al. Longterm lung function following videothoracoscopic talc poudrage for primary spontaneous recurrent pneumothorax. Eur J Cardiothorac Surg. 2007;31:802-5.

6. Hunt I, Barber B, Southon R, Treasure T. Is talc pleurodesis safe for young patients following primary spontaneous pneumothorax? Interact Cardiovasc Thorac Surg. 2007;6:117-20.

7. Vanderschueren RG. [Pleural talcage in patients with spontaneous pneumothorax (author's transl)] [Article in French]. Poumon Coeur. 1981;37:273-6.

8. Sedrakyan A, van der Meulen J, Lewsey J, Treasure T. Video assisted thoracic surgery for treatment of pneumothorax and lung resections: systematic review of randomised clinical trials. BMJ. 2004;329:1008.

9. Light RW. Talc should not be used for pleurodesis. Am J Respir Crit Care Med. 2000;162:2024-6.

10. Horio H, Nomori H, Kobayashi R, Naruke T, Suemasu K. Impact of additional pleurodesis in video-assisted thoracoscopic bullectomy for primary spontaneous pneumothorax. Surg Endosc. 2002;16:630-4.

11. Chappel A, Johnson A, Charles J, Wagner J, Seal R, Berry G, et al. A survey of the long-term effects of talc and kaolin pleurodesis. Research Committee of the British Thoracic Association and the Medical Research Council Pneumoconiosis Unit. Br J Dis Chest. 1979;73:285-8.

12. Wild P. Lung cancer risk and talc not containing asbestiform fibres: a review of the epidemiological evidence. Occup Environ Med. 2006;63:4-9.

13. Ferrer J, Villarino MA, Tura JM, Traveria A, Light RW. Talc preparations used for pleurodesis vary markedly from one preparation to another. Chest. 2001; 119:1901-5

14. Ferrer J, Montes JF, Villarino MA, Light RW, Garcia-Valero J. Influence of particle size on extrapleural talc dissemination after talc slurry pleurodesis. Chest. 2002;122:1018-27.

15. Montes JF, Ferrer J, Villarino MA, Baeza B, Crespo M, Garcia-Valero J. Influence of talc dose on extrapleural talc dissemination after talc pleurodesis. Am J Respir Crit Care Med. 2003;168:348-55.

16. Maskell NA, Lee YC, Gleeson FV, Hedley EL, Pengelly G, Davies RJ. Randomized trials describing lung inflammation after pleurodesis with talc of varying particle size. Am J Respir Crit Care Med. 2004;170:377-82.

17. Kennedy L, Rusch VW, Strange C, Ginsberg RJ, Sahn SA. Pleurodesis using talc slurry. Chest. 1994;106:342-6.

18. Rinaldo JE, Owens GR, Rogers RM. Adult respiratory distress syndrome following intrapleural instillation of talc. J Thorac Cardiovasc Surg. 1983;85:523-6.

19. Milanez JR, Vargas FS, Filomeno LT, Fernandez A, Jatene A, Light RW. Intrapleural talc for the prevention of recurrent pneumothorax. Chest. 1994;106: 1162-5.

20. de Campos JR, Vargas FS, de Campos Werebe E, Cardoso P, Teixeira LR, Jatene FB, et al. Thoracoscopy talc poudrage: a 15-year experience. Chest. 2001;119:801-6

21. Tschopp JM, Boutin C, Astoul P, Janssen JP, Grandin S, Bolliger CT, et al. Talcage by medical thoracoscopy for primary spontaneous pneumothorax is more cost-effective than drainage: a randomised study. Eur Respir J. 2002;20:1003-9. 